\title{
Spermidine Derivatives in Lulo (Solanum quitoense Lam.) Fruit: Sensory (Taste)-vs-Biofunctional (ACE-Inhibition) Properties
}

\author{
Diana Paola Forero, ${ }^{\dagger}$ Chieko Masatani, ${ }^{\ddagger}$ Yoshinori Fujimoto, ${ }^{\ddagger}$ Ericsson Coy-Barrera, $*$ \\ Devin G. Peterson, ${ }^{\S}$ and Coralia Osorio, ${ }^{*}, \dagger$
}

Departamento de Química, Universidad Nacional de Colombia, AA 14490, Bogotá, Colombia

Department of Chemistry and Materials Science, Tokyo Institute of Technology, Meguro, Tokyo 152-8551, Japan

Laboratorio de Química Bioorgánica, Departamento de Química, Facultad de Ciencias Básicas y Aplicadas, Universidad Militar Nueva Granada, AA 49300, Bogotá, Colombia Department of Food Science and Nutrition, 145 Food Science and Nutrition Building, 1334 Eckles Avenue, University of Minnesota, St. Paul, Minnesota 55108, United States

* Author to whom correspondence should be addressed: C. Osorio.

† Departamento de Química, Universidad Nacional de Colombia-Sede Bogotá

${ }^{*}$ Department of Chemistry and Materials Science, Tokyo Institute of Technology

* Laboratorio de Química Bioorgánica, Universidad Militar Nueva Granada, Bogotá, Colombia

${ }^{\S}$ Department of Food Science and Nutrition, University of Minnesota. 
Figure 1S. HPLC analysis and bitter profile of fractions (A) 2.6 , (B) 2.4, and (C) 2.5, from lulo fruit (Bonus- $\mathrm{RP}_{18}$ column, $\lambda=254 \mathrm{~nm}$ ).

(A)

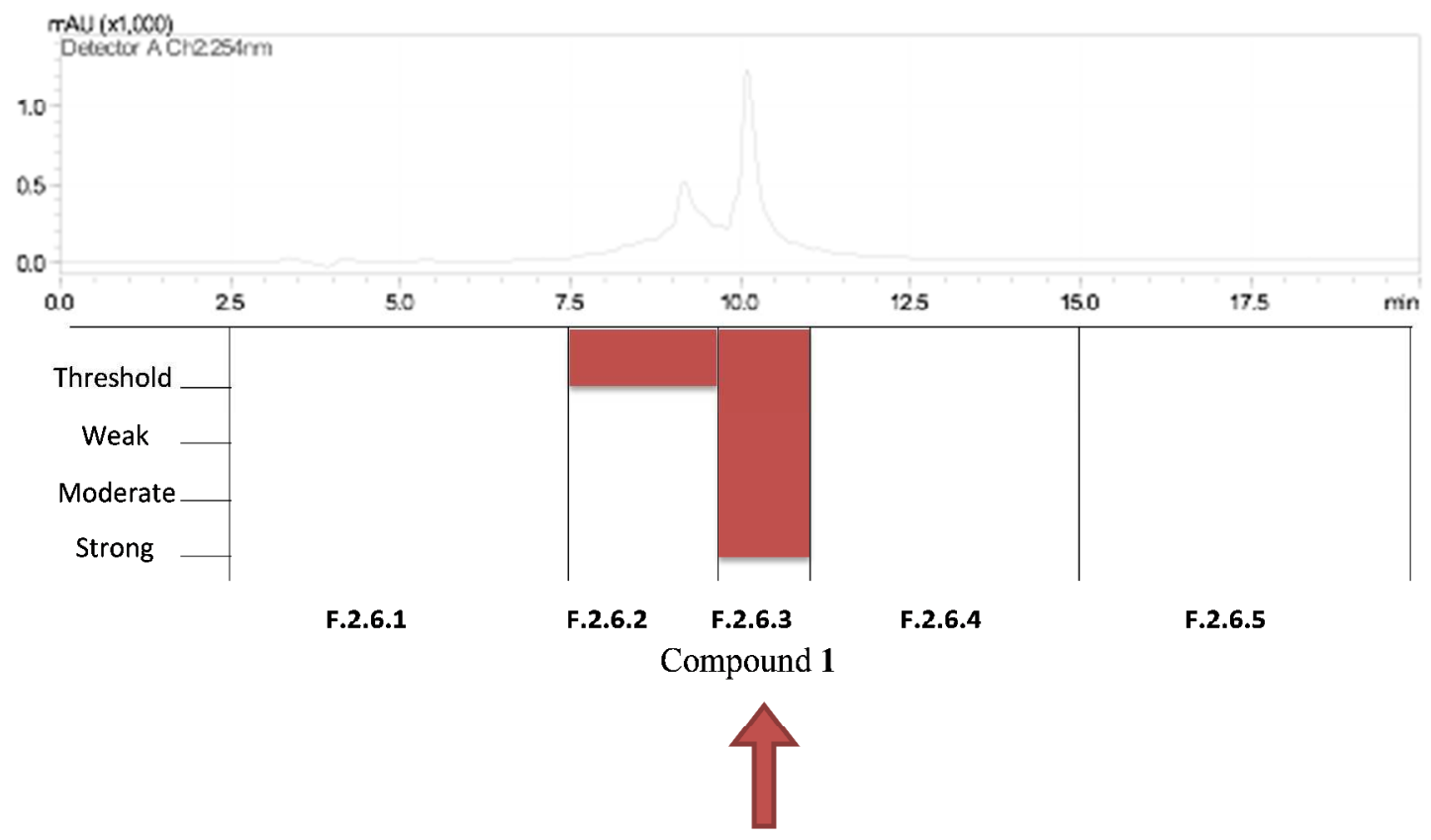

(B)

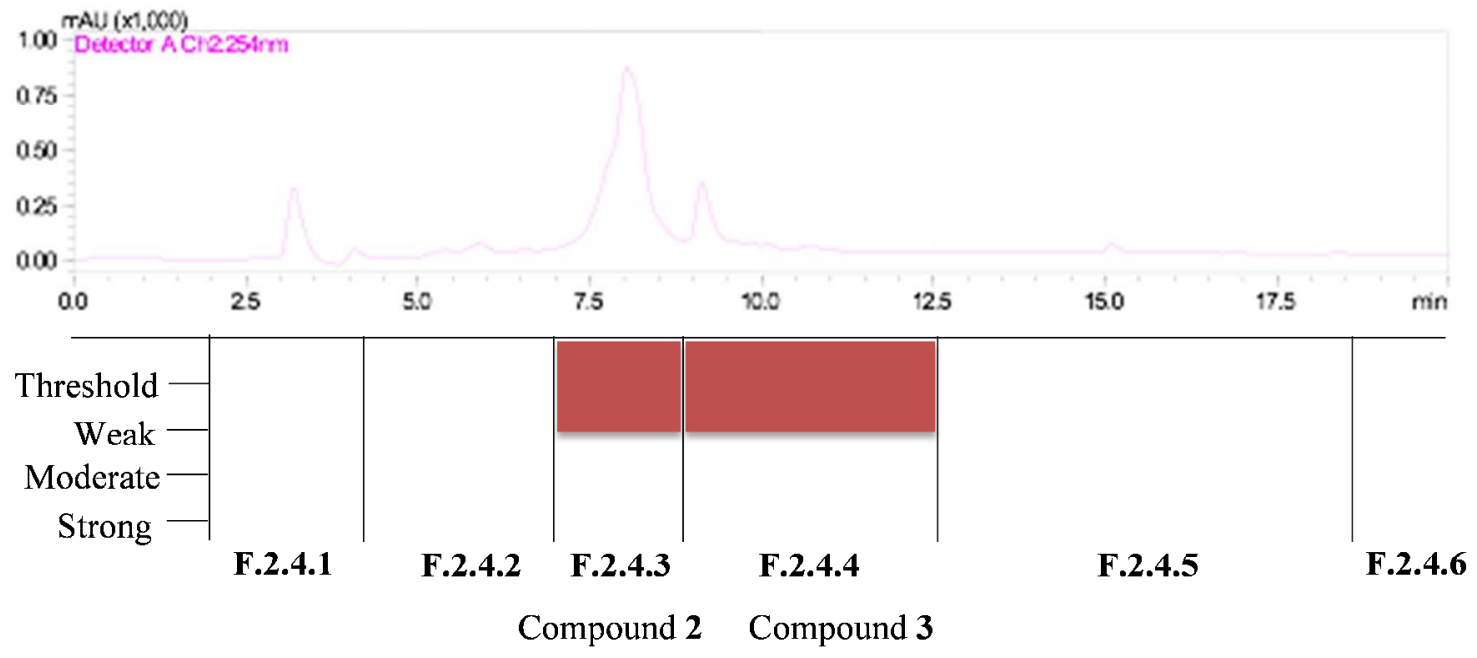


(C)

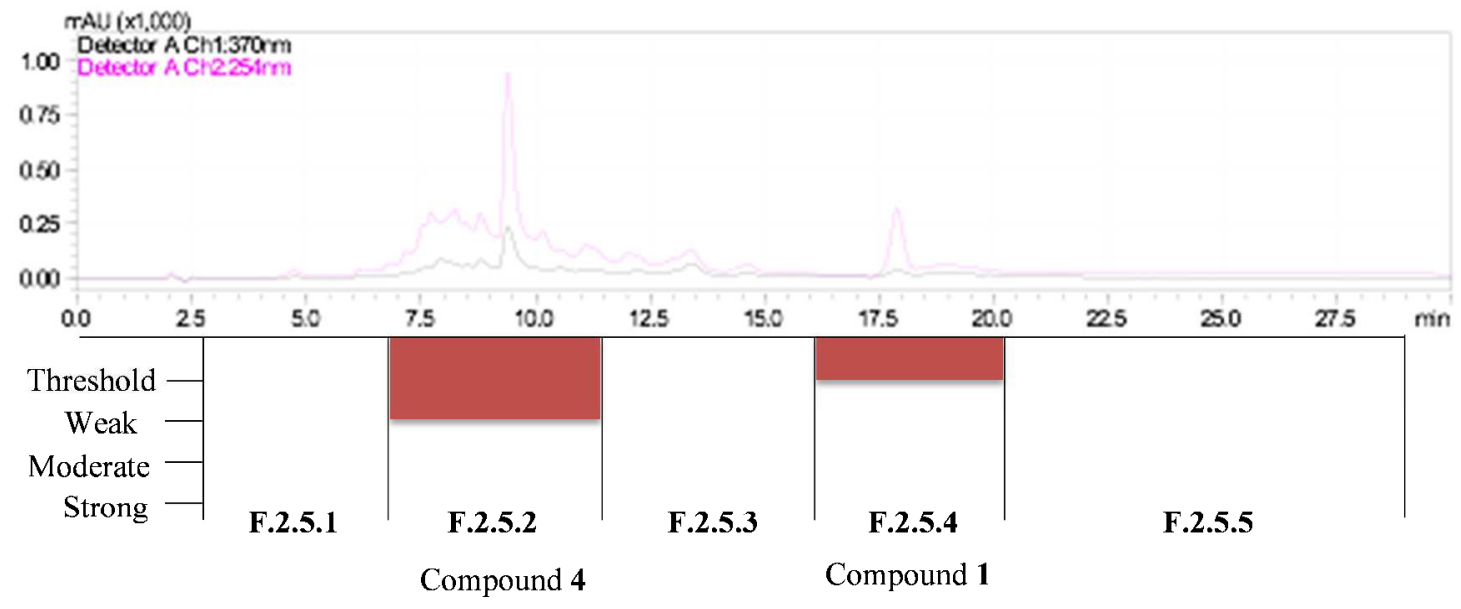

